ARTIGO DE REVISÃO REVIEW ARTICLE

\section{Utilização de medicamentos isentos de prescrição e economias geradas para os sistemas de saúde: uma revisão}

\author{
The use of over-the-counter medicines and cost \\ savings generated for health systems: a review \\ Antonio Cesar Rodrigues \\ DOI: $10.21115 / J B E S . v 9 . n 1 . p 128-36$
}

\section{Palavras-chave: \\ medicamentos isentos de prescrição, MIP, autocuidado, automedicação}

\section{Keywords:}

over-the-counter medications, OTC, self-care, self-medication

\section{RESUMO}

Objetivo: Entender o impacto econômico que os medicamentos isentos de prescrição (MIPs) exercem nos sistemas de saúde e populações da Europa e Américas, em especial no Brasil. Métodos: Revisão bibliográfica cobrindo um período de 20 anos, com artigos identificados pelos serviços PubMed e Lilacs, contendo os termos "automedicação", "medicamentos isentos de prescrição" e "economias", e seus equivalentes na língua inglesa. Resultados: Existe carência na literatura de estudos sobre os impactos econômicos que os MIPs trazem aos países e à sociedade. Os estudos e estatísticas mais abrangentes estão compilados pelas três maiores associações de produtores de MIPs no mundo e demonstram uma aceleração das reclassificações e geração de economias relevantes. No Brasil, um estudo de 2015 utilizando hipóteses conservadoras estimou um impacto orçamentário positivo dos MIPS no Sistema Único de Saúde (SUS) de R\$364 milhões, aproximadamente US\$ 117 milhões. Esse é o único estudo identificado cujo objetivo foi fazer uma quantificação econômica no país. Conclusão: Neste momento em que a RDC n॰ 98/2016 dá a possibilidade para a reclassificação como MIP de um grande número de substâncias farmacêuticas, é imperativo que sejam feitos estudos robustos que estimem todos os impactos econômicos a serem esperados, que poderão servir como elementos para as análises técnicas a serem conduzidas e até mesmo para atribuir graus de prioridade a elas.

\footnotetext{
Recebido em: 02/03/2017. Aprovado para publicação em: 29/03/2017

1. Professor especialista, MBA Internacional - Profuturo da Fundação Instituto de Administração (FIA), São Paulo, SP, Brasil. Nome da instituição onde o trabalho foi executado: Fundação Instituto de Administração (FIA)

Financiamento: $\bigcirc$ presente estudo foi realizado com aporte financeiro da Associação Brasileira da Indústria de Medicamentos Isentos de Prescrição (Abimip).

Conflitos de interesse: $\mathrm{O}$ autor já atuou como consultor ad hoc remunerado para a Associação Brasileira da Indústria de Medicamentos Isentos de Prescrição (Abimip).

Autor correspondente: Antonio Cesar Rodrigues. Fundação Instituto de Administração (FIA). Rua José Alves de Cunha Lima, 172 Vila Butantã, São Paulo/ SP - 05360-050. Telefone: +55 (11) 3732-3501. E-mail: cesar.rodrigues@mac.com
} 


\section{Introdução}

A Declaração de Direitos do Paciente da World Medical Association (WMA) determina, em seu princípio número 9, que: "Todas as pessoas têm o direito a uma educação de saúde que as ajude a fazer escolhas bem informadas sobre sua saúde pessoal e sobre serviços de saúde disponíveis. A educação deve incluir informação sobre estilos de vida saudáveis e sobre métodos de prevenção e detecção precoce de enfermidades. A responsabilidade de todos por sua própria saúde deve ser enfatizada. Médicos têm a responsabilidade de participar ativamente nos esforços educacionais" (WMA, 1981). Sob essa ótica, os medicamentos isentos de prescrição (denominados MIPs daqui em diante) representam uma conquista da sociedade e um importante recurso para que ela possa responsabilizar-se pela própria saúde. A popularidade dos MIPs tem diversas razões: a rapidez no alívio de sintomas menores, a facilidade de acesso, os preços acessíveis e a ampla gama de opções. São eficazes, com posologia simples e em geral seguros e bem tolerados. Diversos MIPs, estando já há décadas no mercado, passaram pela "prova do tempo", mostrando sua relação risco-benefício favorável no mundo real. A sociedade em geral também se beneficia da comunicação de massa empregada pelos MIPs, quando ela inclui informação sobre estilos de vida saudáveis.

Ressalta-se que a Organização Mundial de Saúde (OMS) destaca o papel dos MIPs, conhecidos internacionalmente como medicamentos OTC (over-the-counter), na saúde da população (WHO, 2000). Os MIPs são parte fundamental do autocuidado, uma prática preconizada por essa organização, adotada para manter a saúde e prevenir doenças, e que envolve questões fundamentais, tais como higiene pessoal, qualidade da alimentação, prática de esportes e lazer, entre outros. A melhoria no nível educacional, no conhecimento geral e nas condições socioeconômicas das populações está permitindo que os MIPs sejam integrados aos sistemas de saúde em todo o mundo. Há, porém, uma polêmica sobre quais substâncias devem ser isentas de prescrição, o nível aceitável de tolerabilidade e segurança, o potencial de abuso de certos ingredientes ativos e a ética das propagandas. $\mathrm{O}$ debate sobre o uso de MIPs tem a ver, em certos casos, com o equívoco que existe entre o que é automedicação, dentro do guarda-chuva de autocuidado, e a autoprescrição. A OMS define o que deve ser entendido como autocuidado: "... um recurso de saúde pública principal dentro do sistema de saúde. Ele engloba atividades e decisões de saúde dos indivíduos e inclui a automedicação, o autotratamento, suporte social nas enfermidades e primeiros socorros no dia a dia" (WHO, 2000). Logo, a automedicação é vista como legítima por essa entidade e deve ser entendida como a utilização de medicamentos que, pelo status regulatório, prescindem de receita médica e, assim, podem ser adquiridos livremente pelos consumidores. O termo "automedicação" é usado de forma errônea quando se refere à tomada de medicamentos de prescrição sem receita médica. Trata-se aqui da autoprescrição, o uso de medicamentos sujeitos a receituário por conta própria, conduta de risco pelo perfil de segurança e tolerabilidade que apresentam. Ao praticar o autocuidado, o consumidor faz uso de medicamentos que, por seu perfil de risco-benefício favorável, prescindem de prescrição médica para a compra. No Brasil, as informações ao paciente dos MIPs contêm linguagem acessível, nos termos da Resolução RDC no 47/2009 da Agência Nacional de Vigilância Sanitária (Anvisa), e nas propagandas ressalta-se a necessidade de buscar profissional de saúde caso não desapareçam os sintomas. Quando o autocuidado, o que inclui o uso judicioso de MIPS, é empregado e a autoprescrição é minimizada, há benefícios para a sociedade. Em virtude do frequente uso errado do termo "automedicação", neste trabalho utilizaremos o termo "autocuidado" para referir-nos à prática de uso de MIPs. Um debate sobre o papel dos MIPs na economia da saúde emergiu nos últimos anos, porém os dados são ainda escassos.

\section{Objetivo}

Compreender o impacto econômico que os MIPs exercem nos sistemas de saúde e populações da Europa e Américas, em especial no Brasil.

\section{Métodos}

Para a execução deste trabalho, realizamos como primeiro passo a busca de bibliografia no PubMed, na US National Library of Medicine - National Institutes of Health (https://www. ncbi.nlm.nih.gov/pubmed). Os artigos pesquisados estão dentro de um arco de 20 anos (fevereiro 1997 a janeiro 2017). Os termos buscados foram "self-medication", "over-the-counter" e "savings". Excluímos artigos que continham as palavras "antibiotic", "plants", "children", "elderly", "pregnancy", "advertising", "Asia" ou "Africa". As exclusões objetivaram filtrar grande número de artigos que tratavam de polimedicação em doenças crônicas, anticoncepção emergencial e autoprescrição de antibióticos. Fitoterapia e propaganda de medicamentos também foram excluídas por estarem fora do escopo desta revisão, assim como países da Ásia e África. Neste primeiro passo foram encontrados apenas nove artigos, dos quais somente dois se alinhavam com o objetivo deste trabalho; os outros sete tratavam de produtos de prescrição, uso off label e sistemas de saúde.

Como segundo passo, realizamos busca no Lilacs (http:// lilacs.bvsalud.org/) com os termos "automedicação", "Brasil" e "economias". A busca não resultou em qualquer artigo. Foram feitas também pesquisas substituindo os termos "savings" e "economias" por "losses", "perdas", "costs" e "custos", tentando 
encontrar artigos que fizessem um contraponto com as potenciais economias, e novamente não houve resultados.

Num terceiro passo, buscamos os mesmos termos na internet e obtivemos como resultados principais os sites das três mais importantes associações internacionais de indústrias de MIPs, a saber: World Self-Medication Industry (WSMI - http:// www.wsmi.org), Consumer Health Products Association (CHPA - www.chpa.org) e Association Européenne des Spécialités Pharmaceutiques Grand Public (AESGP - www.aesgp.eu). Nas suas páginas na web buscamos o termo "savings" e, com essa abordagem, foi possível localizar diversas estatísticas e estudos, os quais servirão para guiar esta revisão. Todas as buscas foram realizadas nos meses de fevereiro e março de 2017.

\section{Resultados}

\section{Participação, regulamentação e reclassificação dos MIPs no mundo}

A parcela dos MIPs no mercado farmacêutico total difere bastante entre países e reflete a receptividade da população a esses produtos em função de determinantes culturais, históricos, regulatórios e de infraestrutura da saúde. No Gráfico 1, destaca-se a participação dos MIPs no Brasil, representando 29,3\% das vendas do mercado farmacêutico total. No mundo, as maiores participações dos MIPs encontram-se na Europa Oriental: Rússia com 48,5\%, Ucrânia com 43,9\% e Polônia com $41,8 \%$. A participação desse segmento está impulsionada pela mudança de status regulatório de medicamentos sujeitos à prescrição para MIPs, o que é conhecido como reclassificação, ou switch, na língua inglesa (WSMI, 2009). Nos Estados Unidos, as regulamentações que regem a diferenciação entre produtos que necessitam de prescrição médica e os que prescindem dela existem há décadas, a primeira sendo emitida em 1951, por meio do Durham-Humphrey Amend- ment. Alguns anos mais tarde, o paracetamol ganha status de MIP (WSMI, 2009). A partir da década de 1980, a população europeia gradativamente assume a responsabilidade pelo autocuidado, e nos anos 1990 os governos iniciam a reclassificação de número crescente de ingredientes ativos. No final dos anos 1990 e começo dos anos 2000, o fenômeno acelera-se em outras geografias como Canadá, Austrália e Japão (WSMI, 2009). No Canadá, o movimento de reclassificações já se havia iniciado nos anos 1980, e hoje existe um procedimento análogo ao registro de novos medicamentos para a conversão para MIP. Em 1986, na Austrália, uma lista discriminando substâncias de prescrição, MIPs com venda exclusiva em farmácia e MIPs liberados para venda no varejo em geral é emitida. O país segue um cuidadoso acompanhamento, e medicamentos continuam a ser reclassificados, enquanto alguns voltam a necessitar de receita. Em 2007 o Japão aprova um processo de reclassificação para MIPs, que inclui uma revisão pela Sociedade Farmacêutica Japonesa. As regulamentações introduzidas nos países têm proporcionado clareza e previsibilidade, impulsionando o número de novos entrantes na categoria MIP. Na Tabela 1, exibimos diversas substâncias e suas atuais classificações nas geografias disponíveis na página da Association Européenne des Spécialités Pharmaceutiques Grand Public.

\section{Crescimento no movimento de reclassificação}

Nos últimos dez anos, países vêm acelerando os switches (Gráfico 2), e há de se destacar a disposição de certos países em promovê-los, como a Nova Zelândia, o Reino Unido, a China e a Austrália, todos com dez ou mais substâncias com status de MIP, entre as 13 listadas na Tabela 1. Certos países são notórios em tomar a iniciativa e já iniciam a reclassificação para MIP das estatinas. A sinvastatina já pode ser comprada sem prescrição no Reino Unido (dose máxima de 10 mg/dia)

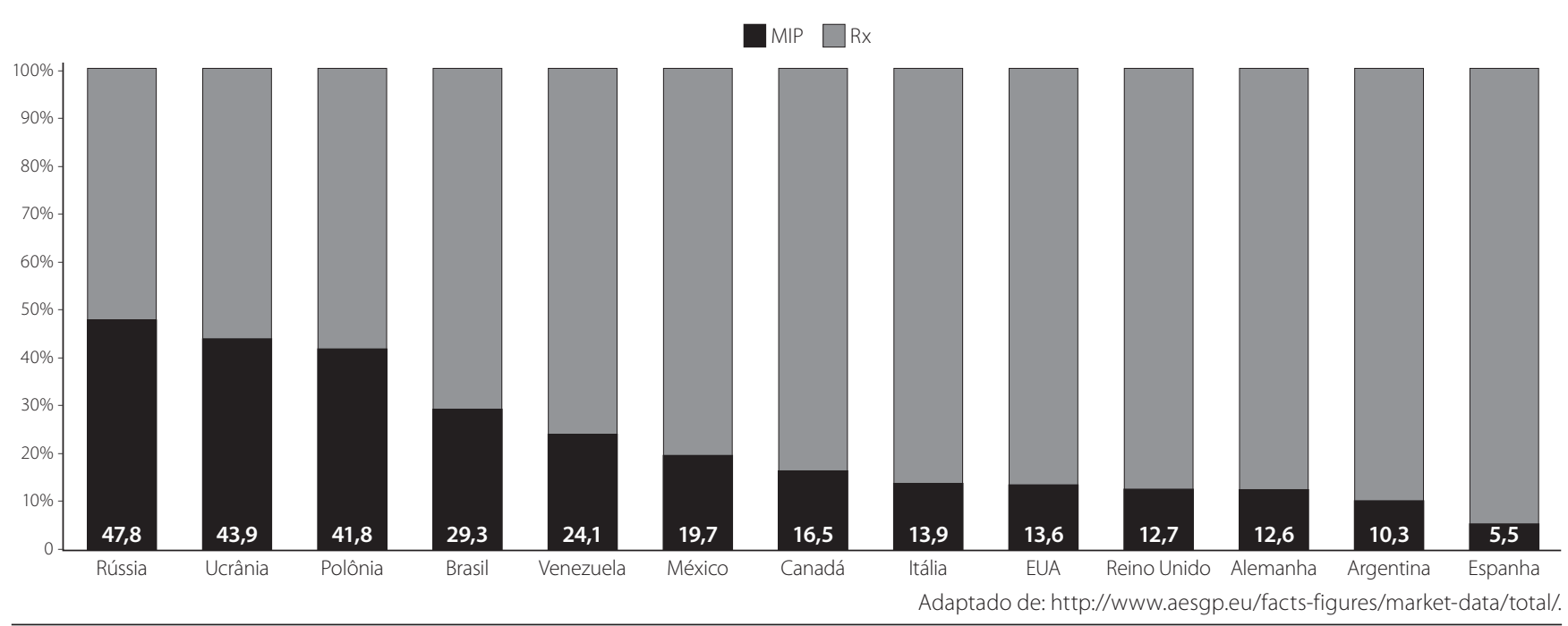

Gráfico 1. Participação do segmento MIP no mercado farmacêutico total - vendas em euro 
Tabela 1. Classificação de substâncias de acordo com exigência de prescrição

\begin{tabular}{|c|c|c|}
\hline Substância & Prescrição & MIP \\
\hline Budesonida & $\begin{array}{l}\text { Alemanha, Argentina, Bélgica, Brasil, Bulgária, Chile, Colômbia, } \\
\text { Coreia do Sul, Croácia, Eslováquia, Eslovênia, Espanha, } \\
\text { Estônia, Filipinas, Finlândia, França, Grécia, Holanda, Hungria, } \\
\text { Irlanda, Itália, Japão, Lituânia, México, Noruega, Polônia }\end{array}$ & Austrália, China, Dinamarca, EUA, Singapura, Nova Zelândia \\
\hline Carbocisteína & $\begin{array}{l}\text { Alemanha, Argentina, Colômbia, Eslovênia, } \\
\text { México, Polônia, Reino Unido }\end{array}$ & $\begin{array}{l}\text { Austrália, Bélgica, Brasil, Bulgária, Chile, China, Coreia do Sul, } \\
\text { Eslováquia, Espanha, Estônia, Filipinas, Finlândia, França, } \\
\text { Grécia, Holanda, Hungria, Irlanda, Itália, Japão, Lituânia, Nova } \\
\text { Zelândia, Portugal, Rep. Tcheca, Singapura, Suiça, Venezuela }\end{array}$ \\
\hline Clorfeniramina & Bulgária, Chile, Eslováquia, Itália & $\begin{array}{l}\text { Alemanha, Argentina, Austrália, Áustria, Brasil, Canadá, } \\
\text { China, Colômbia, Coreia do Sul, Croácia, Dinamarca, } \\
\text { Espanha, Estônia, EUA, Filipinas, França, Grécia, Irlanda, } \\
\text { Japão, Lituânia, México, Nova Zelândia, Polônia, Portugal, } \\
\text { Reino Unido, Rep. Tcheca, Singapura, Suíça, Venezuela }\end{array}$ \\
\hline $\begin{array}{l}\text { Clotrimazol } \\
\text { (vaginal) }\end{array}$ & Brasil, Bulgária, Chile, Eslováquia, Estônia, Grécia, Lituânia, Polônia & $\begin{array}{l}\text { Alemanha, Argentina, Austrália, Áustria, Bélgica, Canadá, China, } \\
\text { Colômbia, Coreia do Sul, Croácia, Dinamarca, Eslovênia, Espanha, } \\
\text { EUA, Filipinas, Finlândia, França, Holanda, Hungria, Irlanda, } \\
\text { Itália, Japão, México, Noruega, Nova Zelândia, Singapura }\end{array}$ \\
\hline Dextrometorfano & Argentina, Brasil, Bulgária, Chile, Grécia & $\begin{array}{l}\text { Alemanha, Austrália, Áustria, Bélgica, Canadá, China, Colômbia, } \\
\text { Coreia do Sul, Croácia, Dinamarca, Eslováquia, Eslovênia, Espanha, } \\
\text { Estônia, EUA, Filipinas, Finlândia, França, Holanda, Hungria, } \\
\text { Irlanda, Itália, Japão, Lituânia, México, Nova Zelândia, Polônia, } \\
\text { Portugal, Reino Unido, Rep. Tcheca, Singapura, Suiça, Venezuela }\end{array}$ \\
\hline Loratadina & Bulgária, Chile, Coreia do Sul, Grécia, Japão, Portugal & $\begin{array}{l}\text { Alemanha, Argentina, Austrália, Áustria, Bélgica, Brasil, } \\
\text { Canadá, China, Colômbia, Croácia, Dinamarca, Eslováquia, } \\
\text { Eslovênia, Espanha, Estônia, EUA, Filipinas, Finlândia, } \\
\text { França, Holanda, Hungria, Irlanda, Itália, Lituânia, México, } \\
\text { Noruega, Nova Zelândia, Polônia, Reino Unido, Rep. } \\
\text { Tcheca, Singapura, Suécia, Suíça, Venezuela }\end{array}$ \\
\hline Lovastatina & $\begin{array}{l}\text { Alemanha, Áustria, Brasil, Bulgária, Chile, China, Colômbia, Coreia } \\
\text { do Sul, Croácia, Dinamarca, Eslováquia, Eslovênia, Espanha, } \\
\text { EUA, Filipinas, Finlândia, Grécia, Itália, México, Noruega, Polônia, } \\
\text { Portugal, Singapura, Reino Unido, Rep. Tcheca, Venezuela }\end{array}$ & Canadá \\
\hline Omeprazol & $\begin{array}{l}\text { Brasil, Chile, Coreia do Sul, Croácia, Dinamarca, } \\
\text { Filipinas, Grécia, Japão, Venezuela }\end{array}$ & $\begin{array}{l}\text { Alemanha, Argentina, Austrália, Áustria, Bélgica, Bulgária, } \\
\text { Canadá, China, Colômbia, Eslováquia, Eslovênia, Espanha, } \\
\text { Estônia, EUA, Finlândia, França, Holanda, Hungria, Irlanda, } \\
\text { Itália, Lituânia, México, Noruega, Nova Zelândia, Polônia, } \\
\text { Portugal, Reino Unido, Rep. Tcheca, Singapura, Suécia, Suíça }\end{array}$ \\
\hline Orlistate & Argentina, Brasil, Canadá, Chile, Colômbia, Coreia do Sul, Venezuela & $\begin{array}{l}\text { Alemanha, Austrália, Áustria, Bélgica, Bulgária, China, Croácia, } \\
\text { Dinamarca, Eslováquia, Eslovênia, Espanha, Estônia, EUA, } \\
\text { Filipinas, Finlândia, França, Grécia, Holanda, Hungria, Irlanda, } \\
\text { Itália, Lituânia, México, Noruega, Nova Zelândia, Polônia, } \\
\text { Portugal, Reino Unido, Rep. Tcheca, Singapura, Suécia, Suíça }\end{array}$ \\
\hline Ranitidina & Brasil, Bulgária, Chile & $\begin{array}{l}\text { Alemanha, Argentina, Austrália, Áustria, Bélgica, Canadá, China, } \\
\text { Colômbia, Coreia do Sul, Croácia, Dinamarca, Eslováquia, } \\
\text { Eslovênia, Espanha, Estônia, EUA, Filipinas, Finlândia, França, } \\
\text { Grécia, Holanda, Hungria, Irlanda, Itália, Japão, Lituânia, } \\
\text { México, Noruega, Nova Zelândia, Polônia, Portugal, Reino } \\
\text { Unido, Rep. Tcheca, Singapura, Suécia, Suíça, Venezuela }\end{array}$ \\
\hline Sinvastatina & $\begin{array}{l}\text { Alemanha, Argentina, Austrália, Áustria, Bélgica, Brasil, Bulgária, } \\
\text { Canadá, Chile, China, Colômbia, Coreia do Sul, Croácia, } \\
\text { Dinamarca, Eslováquia, Eslovênia, Espanha, Estônia, EUA, } \\
\text { Filipinas, Finlândia, França, Grécia, Holanda, Hungria, Irlanda, } \\
\text { Itália, Japão, Lituânia, México, Noruega, Nova Zelândia, Polônia, } \\
\text { Portugal, Rep. Tcheca, Suécia, Singapura, Suiça, Venezuela }\end{array}$ & Reino Unido \\
\hline Sumatriptano & $\begin{array}{l}\text { Alemanha, Argentina, Austrália, Áustria, Bélgica, Brasil, Bulgária, } \\
\text { Canadá, Chile, China, Colômbia, Coreia do Sul, Croácia, Dinamarca, } \\
\text { Eslováquia, Eslovênia, Espanha, Estônia, EUA, Filipinas, França, } \\
\text { Grécia, Holanda, Hungria, Irlanda, Itália, Japão, Lituânia, Noruega, } \\
\text { Polônia, Portugal, Rep. Tcheca, Singapura, Suiça, Venezuela }\end{array}$ & Finlândia, México, Nova Zelândia, Reino Unido, Suécia \\
\hline Triancinolona & $\begin{array}{l}\text { Argentina, Áustria, Brasil, Chile, Colômbia, Croácia, Dinamarca, } \\
\text { Eslováquia, Eslovênia, Estônia, Filipinas, França, Holanda, } \\
\text { Hungria, Irlanda, Lituânia, Polônia, Rep. Tcheca, Venezuela }\end{array}$ & $\begin{array}{l}\text { Alemanha, Austrália, Bélgica, Canadá, China, Coreia do Sul, } \\
\text { Espanha, EUA, Finlândia, Grécia, Itália, Japão, México, Noruega, } \\
\text { Nova Zelândia, Portugal, Reino Unido, Singapura, Suécia, Suíça }\end{array}$ \\
\hline
\end{tabular}

Fonte: http://www.aesgp.eu/facts-figures/otc-ingredients/\#by-name / http://portal.anvisa.gov.br/. Acessado em: 17 fev. 2017. 


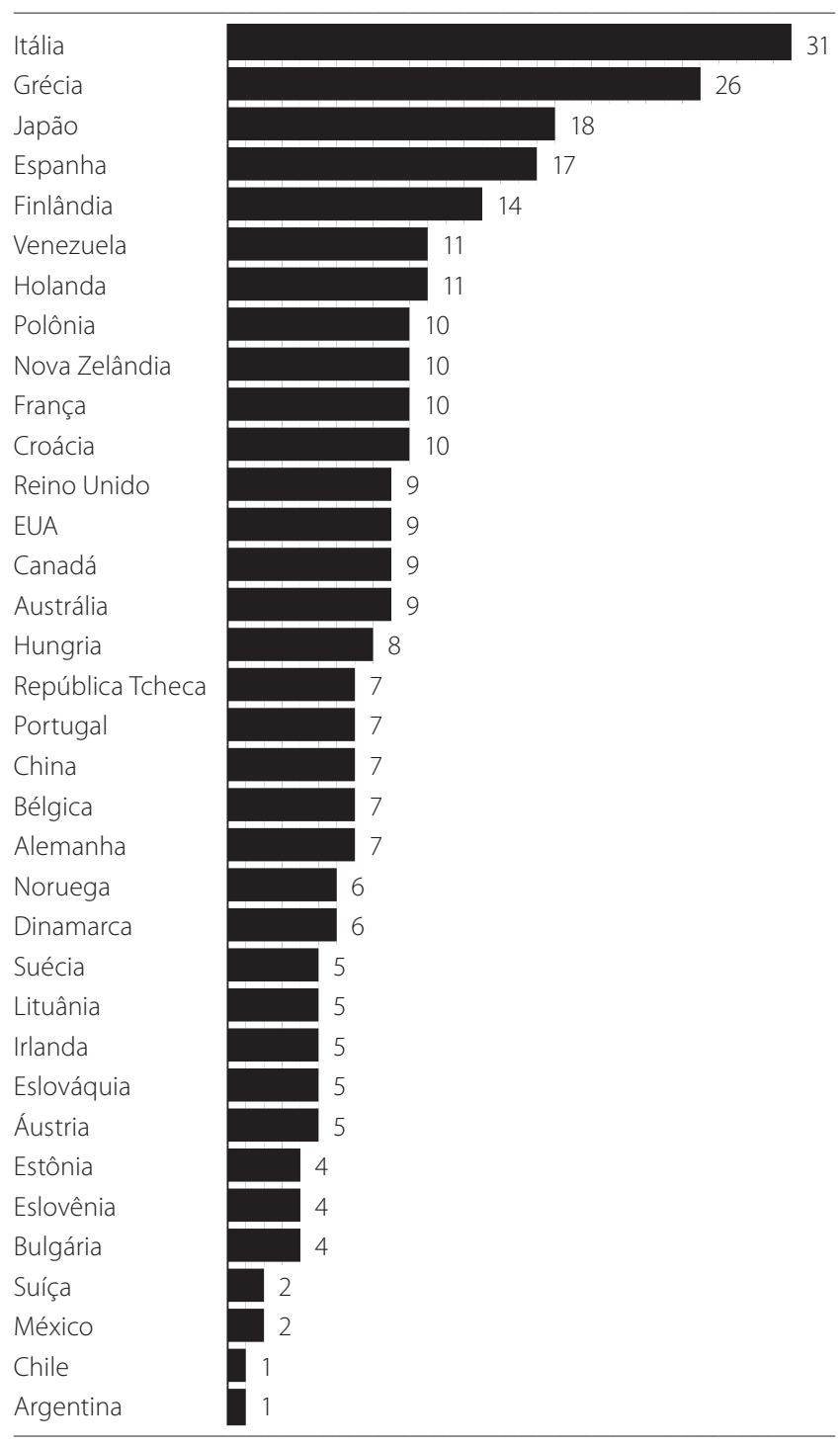

Fonte: http://www.aesgp.eu/facts-figures/otc-ingredients/\#by-parameter.

Gráfico 2. Número de reclassificações para MIPs entre 2007 e 2016.

e é possível adquirir a lovastatina livre de prescrição no Canadá (dose máxima de $1 \mathrm{mg} / \mathrm{dia}$ ). Um switch das estatinas é visto como uma possibilidade nos Estados Unidos quando exames de colesterol rápidos e precisos estejam disponíveis (Brass, 2001). A substância sumatriptana, contra a enxaqueca, pode ser obtida sem prescrição na Finlândia, México, Nova Zelândia, Reino Unido e Suécia. A natureza imprevisível dessa enfermidade torna a isenção de prescrição desejável, pois proporciona maior acessibilidade e reduz o subtratamento (Tfelt-Hansen \& Steiner, 2007). Em comparação, nota-se menor dinamismo no Brasil com respeito ao número de substâncias farmacêuticas reclassificadas, algumas já há décadas com status de MIP em grande número de países. Na lista de 40 países incluídos na Tabela 1, o Brasil é o segundo com menor número de substâncias com status de MIP; das 13 moléculas analisadas, apenas três prescindem de prescrição (AESGP, 2017b; Brasil, 2016). O Chile é o país com menor número de produtos com status de MIP nesse levantamento. Critérios regulatórios historicamente restritivos à reclassificação de moléculas contribuíram sobremaneira para essa situação em nosso país. A publicação da RDC no 98/2016 pela Anvisa, em $1^{\circ}$ de agosto de 2016, representa um divisor de águas, sendo provável que um movimento de reclassificação seja iniciado em breve no país.

\section{A evolução dos MIPs no Brasil}

O baixo número de reclassificações das últimas duas décadas em nosso país pode ser atribuído à Portaria n० 2, de 24 de janeiro de 1995, e à resolução que a revogou, a RDC no 138, publicada pela Anvisa em 29 de maio de 2003. Essa resolução criou um enquadramento para medicamentos livres de prescrição, de acordo com a Lista de Grupos e Indicações Terapêuticas Especificadas (GITE). Dessa maneira, optou-se por abordar a classificação de maneira ampla, citando grupos terapêuticos e indicações em que a prescrição não seria necessária, e não substâncias específicas, as quais apareciam apenas nas observações, para determinar restrições ou permissões. Ainda que a intenção tenha sido possivelmente a de proporcionar flexibilidade, a mudança de status de produto "sujeito à receita médica" para "isento de prescrição" ficou restrita aos grupos especificados na GITE, limitando o movimento de reclassificação. Em $1^{\circ}$ de agosto de 2016, a Anvisa publicou a RDC no 98/2016, que possibilita o pleito de switch para produtos que se enquadram nessa resolução. Por meio dessa regulamentação, ingredientes ativos, e não mais grupos terapêuticos, passam a ser elegíveis ao status de MIP. Para tanto, o produto deve atender a certos critérios, que incluem tempo de comercialização igual ou superior a dez anos, sendo no mínimo cinco anos no Brasil como medicamento sob prescrição e cinco como MIP no exterior. A segurança será considerada apropriada quando as reações adversas forem de causa conhecida e reversíveis com a suspensão de uso e quando houver baixo potencial de toxicidade e de interação medicamentosa e alimentar. O produto deve ser indicado para tratamento, prevenção ou alívio de sintomas de doenças não graves, sem evolução ou de evolução muito lenta, cujos sintomas sejam facilmente identificáveis e que não necessite de monitoramento laboratorial ou consulta médica. Deve ser de curto prazo de utilização, ou de acordo com a bula, excetuando-se produtos de uso preventivo. É necessário que seu manejo seja fácil para o próprio paciente, seu cuidador ou para orientação por um farmacêutico. O candidato a MIP deve oferecer baixo risco de intoxicação, mesmo quando usado de forma equivocada, em quantidades ou por períodos superiores ao indicado. Finalmente, não deve apresentar potencial de causar dependência mesmo em uso normal. Apresentações de uso parenteral foram 
excluídas (Brasil, 2016). A RDC no 98/2016 tem o potencial de mudar consideravelmente o ambiente do autocuidado em nosso país, portanto demanda atenção no seguimento de sua implementação.

\section{Efeitos econômicos proporcionados por MIPs}

A eficácia, conveniência, acessibilidade, segurança, tolerabilidade e riscos potencias dos MIPs já foram discutidos em numerosas publicações, e o balanço favorável faz com que os MIPs sejam considerados como pilares fundamentais nos sistemas de saúde (Schneider et al., 2010). Existe ainda, porém, carência de estudos que proporcionem uma compreensão do papel dos MIPs no âmbito da economia da saúde. São relativamente recentes os estudos de farmacoeconomia que buscam quantificar efeitos de caráter econômico e social para a população. Países europeus têm se destacado pela quantidade de evidência publicada.

\section{Economia nos Estados Unidos}

Um estudo conduzido pela Booz \& Co nos Estados Unidos (CHPA, 2012) concluiu que os MIPs geram uma economia no valor de US\$ 102 bilhões para o sistema de saúde americano a cada ano. Tal valor resulta de serem evitadas consultas médicas desnecessárias (US\$ 66 bilhões), do uso de MIPs de preços mais baixos que medicamentos de prescrição (US\$ 25 bilhões) e da eliminação de exames e terapias dispensáveis (US\$ 11 bilhões). Pelos cálculos desse estudo, cada dólar gasto pelos consumidores em MIP, nos Estados Unidos gera uma economia de US\$ 6 a US\$ 7 para a sociedade americana.

O mesmo estudo revelou que, caso os MIPs retornassem à condição de prescrição, haveria incremento anual de 450 milhões de consultas médicas e que 56.000 médicos adicionais no país seriam necessários. Em 2008, avaliaram-se os ganhos advindos da isenção de prescrição de inibidores da bomba de prótons para o tratamento do refluxo (Mansfield \& Callahan, 2008), sendo o resultado economia de US\$ 757 milhões para a sociedade.

\section{Impacto econômico na União Europeia}

O impacto orçamentário na saúde em seis países europeus (Alemanha, Espanha, França, Itália Polônia e Reino Unido) foi calculado para uma possível migração da classe dos triptanos (antienxaqueca) para a condição de MIPs. O modelo utilizado levou em consideração os custos dos medicamentos, consultas médicas, pronto atendimento e perda de produtividade. A economia gerada nesses países seria de 75,3 milhões de euros por ano, na perspectiva do pagador, e de 86,4 milhões de euros por ano, na perspectiva da sociedade em geral (Millier et al., 2013). Em trabalho anterior englobando países da União Europeia (Alemanha, Áustria, Espanha, França, Itália, Portugal e Reino Unido) e Suiça, concluiu-se que: "Nos sete países estudados, a pou- pança total para os orçamentos públicos e para as economias nacionais advinda da reclassificação de medicamentos prescritos para a automedicação responsável totaliza 11,5 bilhões de euros". Projeções feitas nesse estudo para todos os países europeus sugerem uma economia de 16,4 bilhões (AESGP, 2004).

\section{Resultados econômicos da reclassificação em outros países}

A AESGP proporcionou uma projeção de economias em outros países europeus por meio de switches, que destacamos abaixo. A Association Française de I'Industrie Pharmaceutique pour une Automédication Responsable (Afipa) estimou, em estudo de 2011, uma economia de 130 milhões de euros caso sete substâncias com status de MIP em outros países europeus sofressem switch (AESGP, 2012). No Reino Unido, análise baseada em 4 milhões de fichas de pacientes (anônimos) determinou que 20\% das consultas com clínicos gerais diziam respeito a enfermidades menores, definidas nesse estudo como dor lombar, tosse, resfriado, dor de cabeça, dor de dente, indigestão, problemas de pele e rinite alérgica. Somente as consultas médicas representavam um custo de 1,8 bilhão de libras esterlinas; parte desse custo social poderia ser reduzido com a reclassificação proposta para os MIPs (PAGB, 2009). Dores lombares, uma das queixas não sérias mais comuns, foi objeto de estudo levado a cabo na Bélgica em 2006. Utilizando-se de modelo probabilístico, calcularam-se economias potenciais de 30 milhões de euros ao ano geradas com o autocuidado nesse diagnóstico (AESGP, 2012). Pesquisa finlandesa de 2008 calculou possíveis economias de 5,5 milhões de euros para a seguridade social numa reclassificação de antialérgicos e uma poupança de 20 a 25 milhões de euros pela prática do autocuidado nas infecções vaginais microbianas (AESGP, 2012). Para a Holanda, as consultas médicas com clínicos gerais para doenças não graves em 2009 geraram um custo próximo a 100 milhões de euros (AESGP, 2012). Estudo apresentado no $18^{\circ}$ Congresso Europeu da ISPOR projetou que economias de 3,1 bilhões de euros, num arco de três anos, poderiam ser geradas na Espanha caso ocorresse uma reclassificação para MIPs de uma série de grupos terapêuticos (Pellise \& Serra, 2015). A Associazione Nazionale dell'Industria Farmaceutica dell' Automedicazione (Anifa), estimou, em 2009, uma economia anual entre 63 e 300 milhões de euros, possível por meio da reclassificação na Itália (AESGP, 2012).

\section{Uso de MIPs no Brasil e cálculo de impacto no SUS}

O papel dos MIP na utilização dos recursos da saúde pública apenas começa a ser abordado no Brasil. Tomando-se por base a experiência de outros países, os MIPs têm o potencial de diminuir o número de visitas desnecessárias 
às unidades de pronto atendimento, desafogar o sistema de saúde, evitar perdas de dias de trabalho e diminuir o volume de exames laboratoriais desnecessários. Os MIPs utilizados com esclarecimento da população e responsabilidade podem gerar economias, entretanto, para obter uma visão mais abrangente, haveria também que se incorporar nas análises consequências não desejáveis que o uso inadequado dos MIPs pode acarretar. A metodologia de busca revelou apenas um estudo que abordou o papel dos MIPs no Brasil pelo ângulo econômico, o qual foi apresentado no $20^{\circ}$ Congresso Anual da International Society for Pharmacoeconomics and Outcomes Research na Philadelphia, Estados Unidos, e utilizou cifras de consultas ambulatoriais no Sistema Único de Saúde (SUS), dados do Ministério do Trabalho e informações de consumo de MIPs no Brasil da auditoria internacional IMS Health. Hipóteses que podem ser consideradas como conservadoras foram empregadas, chegando-se ao total de 5,1 milhões de consultas que podem ser evitadas com uso responsável de MIPs. As economias líquidas geradas seriam de $\mathrm{R} \$ 364,1$ milhões (Tabela 2) para a sociedade (Ferreira et al., 2015).

A economia calculada neste estudo ocorre ao se evitarem gastos desnecessários em consultas (R\$ 56,1 milhões) e perda de dias trabalhados (R\$369,2 milhões), deduzindo-se como contrapartida o custo dos MIPs para o consumidor (R\$ 61,2 milhões), o que resulta numa economia de $\mathrm{R} \$ 364,1$ milhões. O trabalho incorpora também uma ótica de retorno de investimento: a sociedade investiu $R \$ 61,2$ milhões na aquisição de MIPs e deixou de gastar $R \$ 425,3$ milhões, o que equivale a um ratio aproximado de $1 / 7$. Ou seja, cada $R \$ 1,00$ gasto num MIP resultou numa economia de até $\mathrm{R} \$ 7,00$, uma proporção similar à observada no estudo realizado pela Booz \& Co nos Estados Unidos (CHPA, 2012).

\section{Conclusão}

A aceleração das reclassificações para status de MIP que vem ocorrendo no mundo pode ser atribuída, ao menos em parte, às economias proporcionadas aos países. É possível que uma implementação efetiva da RDC no 98/2016 venha também a gerar economias para a saúde pública e para a sociedade brasileira, porém ela dependerá da dinâmica dos diversos atores: a indústria farmacêutica, as autoridades regulatórias, os profissionais de saúde e a população. O monitoramento feito pelos sistemas de vigilância sanitária será também fundamental para o sucesso da nova regulamentação, ao identificar qualquer distorção que ocorra na comercialização dos novos MIPs. Possíveis impactos econômicos da RDC no 98/2016 têm relevância: a reclassificação de inibidores da bomba de prótons como o omeprazol, que possui status de MIP em mais de 30 países (Tabela 1), poderia gerar uma poupança de R\$ 93 milhões ao ano para o Brasil (Tabela 3). O trabalho com dados brasileiros discutido anteriormente foi um passo inicial. Mais e melhores estudos são necessários para fornecer uma compreensão mais ampla e profunda sobre os impactos de caráter econômico dos MIPs em nosso país.

\section{Limitações}

Os estudos sobre o impacto econômico dos MIPs são pouco numerosos e pouco citados. Para suprir a lacuna bibliográfica, nos valemos de informações e referências disponíveis em websites das três associações de indústrias produtoras de MIPs mais importantes no mundo. Dessa maneira, não se pode descartar a hipótese de que algum viés favorável à magnitude das economias obtidas pelos MIPs haja sido introduzido. Existem dois aspectos de difícil quantificação para

Tabela 2. Cálculo do valor dos MIPs para o Sistema Único de Saúde

\begin{tabular}{|c|c|c|}
\hline Descrição & Valor & Fonte \\
\hline (a) Consultas que resultaram em prescrições com MIP & 51.000 .000 & $\begin{array}{l}\text { Datasus - Produção Ambulatorial do SUS/CHPA. } \\
\text { "Briefing Information on the Rx-to-OTC Switch Process" } \\
\text { 22/10/2012. http://www.chpa.org/SwitchProcess.aspx. }\end{array}$ \\
\hline $\begin{array}{l}\text { (b) Consultas relativas a doenças comuns; medicamentos } \\
\text { poderiam ser adquiridos sem receita (a) x 10\% }\end{array}$ & 5.100 .000 & Ferreira et al., 2015 \\
\hline (c) Custo de consulta médica no SUS & $\mathrm{R} \$ 11,00$ & Tabela Unificada SAI-SIH-SUS - Sigtap 3.0.1.3 \\
\hline $\begin{array}{l}\text { (d) Gastos em consultas médicas } \\
\text { desnecessárias no SUS (b) × (c) }\end{array}$ & $R \$ 56.100 .000$ & \\
\hline (e) Custo médio de dia de trabalho & $\mathrm{R} \$ 72,40$ & Portal do Ministério do Trabalho \\
\hline (f) Perdas por dias não trabalhados (b) x (e) & $R \$ 369.240 .000$ & \\
\hline (g) Economia bruta pelo uso de MIP (d) + (f) & $R \$ 425.340 .000$ & \\
\hline (h) Custo médio de uma compra de MIPs em farmácias & $(R \$ 12,00)$ & IMS Health -Internal Data OTC \\
\hline (i) Gastos com MIPs (b) x (h) & $(R \$ 61.200 .000)$ & \\
\hline ECONOMIA LÍQUIDA PELO USO DE MIP (g) + (I) & $R \$ 364.140 .000$ & \\
\hline
\end{tabular}


Tabela 3. Estimativas de economias pela reclassificação do omeprazol (cálculos do autor)

\begin{tabular}{|c|c|c|}
\hline Descrição & Valor & Fonte \\
\hline (a) Número de endoscopias realizadas pelo SUS em 2016 & 1.828 .970 & $\begin{array}{l}\text { DATASUS - Produção Ambulatorial do SUS - } 2016 \text { - http:// } \\
\text { tabnet.datasus.gov.br/cgi/tabcgi.exe?sia/cnv/qauf.def }\end{array}$ \\
\hline (b) Endoscopias e consultas desnecessárias & $25 \%$ & Allen, 2012 \\
\hline (c) Custo do exame de endoscopia x 1 & $R \$ 48,16$ & $\begin{array}{l}\text { Datasus - Sigtap. Procedimento 02.09.01.003- } \\
\text { 7. Competência 02/2017 }\end{array}$ \\
\hline (d) Custo de consulta médica ambulatorial no SUS x 2 & $R \$ 20,00$ & $\begin{array}{l}\text { Datasus - Sigtap. Procedimento 03.01.01.007- } \\
\text { 2. Competência 12/2016 }\end{array}$ \\
\hline (e) Remuneração média por dia de trabalho x 2 & $\mathrm{R} \$ 177,03$ & $\begin{array}{l}\text { Ministério do Trabalho } \\
\text { ftp://ftp.mtps.gov.br/pdet/rais/2015/ } \\
\text { nacionais/4-resultadosdesagregados.xls }\end{array}$ \\
\hline $\begin{array}{l}\text { (f) Economias em consultas, diagnósticos, } \\
\text { absenteísmo e retornos } \\
{[(\mathrm{a}) \times(\mathrm{b})] \times[(\mathrm{c})+(\mathrm{d})+(\mathrm{e})]}\end{array}$ & $\mathrm{R} \$ 112.111 .289$ & \\
\hline (g) Custo médio de omeprazol genérico 20 mg com $28 \mathrm{cp}$ & $(\mathrm{R} \$ 41,44)$ & https://consultaremedios.com.br/omeprazol-medley/p \\
\hline (h) Gastos com omeprazol MIP (a) x (b) x (g) & (R\$ 18.948.129) & \\
\hline ECONOMIA COM OMEPRAZOL COMO MIP (f) + (h) & $R \$ 93.163 .160$ & \\
\hline
\end{tabular}

avaliar efeitos econômicos da utilização de MIPs em sua totalidade. Pode-se aventar a hipótese de que os MIPs posterguem a resolução de problemas de saúde que demandam pronta atenção ou que favoreçam o subtratamento, trazendo consequências negativas no longo prazo. Por outro lado, existe o pressuposto de que, ao desafogar recursos da saúde, os MIPs possibilitem maior número de atendimentos a pacientes com enfermidades sérias, gerando economia ao evitar futuras internações. Em ambos os casos não foram encontradas evidências concretas na literatura disponível.

\section{Agradecimentos}

Meus agradecimentos à diretoria da Associação Brasileira de Medicamentos Isentos de Prescrição (Abimip), pelo suporte proporcionado para a condução deste trabalho, sem o qual ele não seria possível.

\section{Referências bibliográficas}

AESGP - Association Européenne des Spécialités Pharmaceutiques Grand Public. Innovation key to driving OTC market. OTC Bulletin. 2014. Disponivel em: <http://www.otc-bulletin.com//media/1007/innovationkey-to-driving-otc-market.pdf>. Acessado em: 3 out. 2016.

AESGP - Association Européenne des Spécialités Pharmaceutiques Grand Public. Market data. 2017a. Disponível em: <http://www.aesgp.eu/ facts-figures/market-data/non-prescription-market/>. Acessado em: 13 fev. 2017.

AESGP - Association Européenne des Spécialités Pharmaceutiques Grand Public. OTC ingredients. 2017b. Disponível em: <http://www.aesgp.eu/ facts-figures/otc-ingredients/\#by-name>. Acessado em: 17 fev. 2017.
AESGP - Association Européenne des Spécialités Pharmaceutiques Grand Public. Self-care: a winning solution. 2012. Disponível em: <http://www. aesgp.eu/media/cms_page_media/68/Self-Care\%20A\%20Winning\%20 Solution.pdf $>$. Acessado em: 19 fev. 2017.

AESGP - Association Européenne des Spécialités Pharmaceutiques Grand Public. The economic and public health value of self-medication. 2004. Disponível em: <http://www.aesgp.eu/media/cms_page_ media/68/2004study.pdf>. Acessado em: 19 fev. 2017.

Allen JL. Endoscopy for gastroesophageal reflux disease: choose wisely. Ann Intern Med. 2012;157(11):827-8.

Brasil. Ministério da Saúde (MS). Agência Nacional de Vigilância Sanitária (Anvisa). Brasília, DF. Resolução da Diretoria Colegiada - RDC no 98, de 10 de agosto de 2016. Disponível em: <http://portal.anvisa.gov.br/ documents/10181/2921766/RDC_98_2016.pdf/32ea4e54-c0ab-459d903d-8f8a88192412>. Acessado em: 6 ago. 2016.

Brass EP. Changing the status of drugs from prescription to over-the-counter availability. N Engl J Med. 2001;345(11):810-6.

CHPA - Consumer Health Products Association. The value of OTC medicine to the United States. 2012. Disponível em: <http://www. yourhealthathand.org/images/uploads/The_Value_of_OTC_Medicine_ to_the_United_States_BoozCo.pdf>. Acessado em: 18 fev. 2017.

Ferreira CN, Santana CF, Rufino CS. The value of OTC medicines in Brazilian Public Health System (SUS). ISPOR 20th Annual International Meeting. 2015. Disponível em: <https://www.ispor.org/ScientificPresentationsDatabase/ Presentation/55298>. Acessado em: 19 fev. 2017.

Mansfield JE, Callahan D. Benefits of over-the-counter heartburn medication to consumers and the healthcare system. NielsenHealth. 2008. Disponível em: <https://www.chpa.org/01_26_09_ NielsenReportHeartburn.aspx>. Acessado em: 19 fev. 2017.

Millier A, Cohen J, Toumi M. Economic impact of a triptan Rx-To-OTC switch in six EU countries. PLoS One. 2013;8(12):e84088.

PAGB - Proprietary Association of Great Britain. Making the case for the self-care of minor ailments. Londres, Inglaterra. 2009. Disponível em: <http://www.selfcareforum.org/wp-content/uploads/2011/07/ Minorailmentsresearch09.pdf>. Acessado em: 30 mar. 2017. 
Pellise L, Serra M. The Economic Impact of an Hypothetical Rx-To-otc Switch in Spain. Value Health. 2015;18(7):A341.

Schneider H, Roehrig RC, Coppolecchia R, Ming D, Garwin J, Qi D, et al. White paper on the benefits of OTC medicines in the United States - Report of the Consumer Healthcare Products Association's Clinical/Medical Committee. Pharmacy Today. 2010. Disponível em <http://www.yourhealthathand.org/ images/uploads/r_6842.pdf>. Acessado em: 18 fev. 2017.

Tfelt-Hansen P, Steiner TJ. Over-the-counter triptans for migraine: what are the implications? CNS Drugs. 2007;21(11):877-83.

WHO - World Health Organization. WHO Drug Information. 2000;14(1).

Disponível em: <http://apps.who.int/medicinedocs/pdf/h1462e/h1462e. pdf>. Acessado em: 18 fev. 2017.
WMA - World Medical Association. WMA Declaration of Lisbon on the Rights of the Patient. 1981. Disponivel em: <https://www.wma.net/policiespost/wma-declaration-of-lisbon-on-the-rights-of-the-patient/>. Acessado em: 18 fev. 2017.

WSMI - World Self-Medication Industry. SWITCH - Prescription to nonprescription medicines switch. 2009. Disponível em: <http://www. wsmi.org/wp-content/data/pdf/wsmi_switchbrochure.pdf>. Acessado em: 15 fev. 2017. 